AlAA Guidinca. Navigation, and

Control Conference and Exhibit

14-17 August 2000 Demer, CO

\section{A00-37004}

AIAA 2000-3942

\title{
A Reconfiguration Scheme for Ačcommodating Actuator Failures in Multi-Input, Multi-Output Flight Control Systems
}

\author{
W. Siwakosit ${ }^{\prime}$ and R.A. Hess ${ }^{2}$ \\ Dept. of Mechanical and Aeronautical Engineering \\ University of California \\ Davis, CA 95616
}

\begin{abstract}
A multi-input,

multi-output

reconfigurable flight control system design utilizing a robust controller and an adaptive filter is presented. The robust control design consists of a reduced-order, linear dynamic inversion controller with an outer-loop compensation matrix derived from Quantitatitve Feedback Theory (QFT). A principle feature of the scheme is placement of the adaptive filter in series with the QFT compensator thus exploiting the inherent robustness of the nominal flight control system in the presence of plant uncertainties. An example of the scheme is presented in a pilot-in-the-loop computer simulation using a simplified model of the lateral-directional dynamics of the NASA F18 High Angle of Attack Research Vehicle (HARV) that included nonlinear anti-windup logic and actuator limitarions. Prediction of handling qualities and pilot-induced oscillation tendencies in the presence of these nonlinearities is included in the example.
\end{abstract}

\section{Introduction}

Damage to the actuators driving the control effectors of a modem aircraft can adversely affect the performance and stability of the vehicle. Indeed, the design of future, highperformance aircraft will likely include some ability to automatically reconfigure the aircraft flight control system in the presence of failure or damage to the actuators. Because of this evolving requirement, reconfigurable flight control is an active research area, see for example Refs 1-8.

The research to be described will focus on the problem of recovering performance in the presence of actuator failures. The methodology to be described will allow continuous pilot control during reconfiguration, a significant improvement over some of the approaches that have preceded it, i.e., Refs. 6 and 8 . In addition, reconfiguration in the presence of significant nonlinearities stemming from actuator amplitude and rate limitations will be demonstrated as will the handling qualities and pilot-induced oscillation (PIO) prediction technique offered in Refs. 9 and 10.

Considering the type of damage that can accrue in aircraft, particularly combat aircraft, focusing upon actuator damage/failures alone may seem an unwarranted simplification. However, the control effectors that are actuated by these devices are powerful aerodynamic/propulsive force and moment producers. Thus, a design methodology capable of accommodating actuator failures may also be a candidate for handling other type of damage, e.g., that associated with the airframe, itself.

\section{Methodology}

The proposed flight control system will be designed based on a Quantitative Feedback

\footnotetext{
'Graduate Student

${ }^{2}$ Professor and Vice Chairman, Associate Fellow AIAA

Copyright $(\mathcal{O}$ by W. Siwakosit and R. A. Hess. Published by the American Institute of Aeronautics and Astronautics, Inc. with permission.
} 
Theory/Pre-Design Technique (QFT/PDT)" and a reduced-order, linear, dynamic inversion (RLDI) controller. ${ }^{12,13}$ Although reconfigurable control was not the goal in the study summarized in Ref. 13, the QFT/PDT and RLDI controllers developed therein were shown to provide stability and performance robustness to significant uncertainties in the vehicle model. This robustness made the controllers ideal candidates to serve as a base-line nominal controller for the reconfigurable system to be described. The only modification of the design of Ref. 13 was the inclusion of adaptive filtering in series with the QFT/PDT compensator. As such, the design can be thought of as an adaptive QFT system. Figure 1 shows the general topology of the feedback system just described.

Failure detection is not addressed in the discussion to follow. It is assumed that the reconfiguration logic is operating at all times and adjusting to performance degradations arising from actuator failures. The system could, of course, be employed in conjunction with a failure detection algorithm that activates the reconfiguration logic upon identification of a failure. The reconfiguration logic does not, however, require identifying which actuator(s) has failed.

\section{RLDI}

For undamaged aircraft, the QFT/PDT procedure can produce unacceptably high-gain controllers when applied across the entire flight envelope. This tendency will be eliminated by gain scheduling a RLDI. This technique can provide desired input-output dynamics over the flight envelope including approximate decoupling of the control channels. The gain scheduling process is straightforward and the formulation of RLDI has already been demonstrated. ${ }^{12}$ After design of the RLDI, the QFT/PDT compensation provides additional performance robustness lost due to uncertainties in the vehicle model use to obtain the RLDI. In addition, the QFT/PDT compensator can provide at least stability robustness in the presence of a class of actuator failures.

\section{OFT/PDT}

The Quantitative Feedback Theory (QFT) Pre-Design Technique (PDT) was introduced and fully discussed in Ref. 11. The PDT will give an estimation of a QFT controller that will satisfy the performance specifications in the presence of plant uncertainties. In some cases, a formal QFT design may not be necessary if the PDT provides satisfactory results. The design of the QFT/PDT controller will be based upon the dynamics of undamaged aircraft and will ensure satisfactory handling qualities with no pilot-induced oscillation (PIO) tendencies. Its structure will not be altered during reconfiguration.

\section{Adaptive Filtering}

The reconfiguration scheme will utilize the Widrow-Hopf Least Mean Square (LMS) algorithm ${ }^{14}$ in an adaptive form called the filtered$\varepsilon$ LMS algorithm. ${ }^{15}$ This algorithm resembles a model-reference adaptive control scheme that minimizes the square of the difference between the output of the system and the output of the selected model. Figure 2 shows the structure of the adaptive filter and Fig. 3 shows the filtered- $\varepsilon$ LMS algorithm. Analyses of stability, rate of convergence, and noise effects in the weights for the filtered- $\varepsilon$ LMS algorithm shown in Fig. 3 are discussed in Ref. 15.

The algorithm for updating the filter weights has the following structure,

$$
W_{k+1}=W_{k}+2 \mu X_{k} \varepsilon_{k}
$$

where

$$
\begin{aligned}
\mathbf{x}_{k} & =\left[\begin{array}{c}
\mathbf{x}_{k} \\
x_{k-1} \\
\vdots \\
x_{k-L}
\end{array}\right], \\
\mathbf{w}_{k} & =\left[\begin{array}{c}
w_{0 k} \\
w_{l k} \\
\vdots \\
w_{L k}
\end{array}\right]
\end{aligned}
$$

and

$$
\begin{aligned}
& \varepsilon_{k}=d_{k}-X_{k}^{T} W_{k}=d_{k}-W_{k}^{\top} X_{k} \\
& d_{k}=\text { desired response } \\
& L+1=\text { number of weights } \\
& x_{k}=\text { input to an adaptive filter } \\
& \left.W_{i k}\right|_{i=0,1,2, \ldots, L}=\text { adaptive weights } \\
& y_{k}=\text { output from an adaptive filter }= \\
& X_{k}^{T} W_{k}=W_{k}^{T} X_{k}
\end{aligned}
$$


Equation 1 is the LMS algorithm. ${ }^{14.15}$ In this form, the LMS algorithm can be implemented in a practical system with simplicity. It can be shown that convergence of the weight vector is obtained by appropriate selection of $\mu$ and $L$ in Eq. 1. 14,19

The filtered- $\varepsilon$ LMS algorithm can be applied to multi-input, multi-output (MIMO) systems. ${ }^{19}$ As can be seen from Fig. 3, estimation of the inverse plant model, $\hat{\mathrm{P}}^{-1}$ is required in order to implement this scheme. Off-line estimation of $\dot{p}^{-1}$ can be accomplished with inverse plant modeling, but may not be possible in - some situations, e.g. in the reconfigurable flight control problem. However, the exactness of the $\hat{\mathrm{p}}^{-1}$ is not critical to the convergence of the adaptive filter in Fig. 3. As will be demonstrated, an approximation to $\dot{p}^{-1}$ can be employed with no off-line or on-line inverse modeling of the plant. An approximation to $\dot{\mathrm{p}}^{-1}$ will not be changed during adaptation and can be a very rough estimate of the dynamics of the damaged aircraft. $^{16}$ In linear systems, the adaptive algorithm will converge to an absolute minimum. If the system in question is nonlinear, convergence of $\mathrm{Eq} . \mathrm{I}$ to an absolute minimum is not guaranteed, i.e., only a relative minimum may be obtained.

Herein, the reference model selected in the reconfiguration scheme will have the desired dynamics of the decoupled system as obtained from the dynamic inversion of the nominal system. In this way, the adaptive filter will be attempting to recreate the dynamics prescribed by the RLDI when operating with the nominal vehicle. Recall also that the adaptation does not have to be exact, since the robust QFT/PDT controller will accommodate imperfections (uncertainty) in the inner-loop reconfiguration. Finally, the proposed scheme doe not require detection of the failed actuators since the modified filtered- $\varepsilon$ scheme does not need identification of the failed system.

\section{Conditions for Successful Reconfiguration}

Successful reconfiguration depends upon the following conditions being met:

1.) The dynamic inversion loop remains stable after actuator failure occurs.

2.) In the presence of actuator failures, the aircraft will still be controllable by virtue of redundant effectors.
The aircraft with a nominal control structure that meets these criteria will be reconfigurable using the proposed scheme.

\section{Simulation of Pilot-in-the-Loop Control}

The ability to function under continuous pilot control is an important attribute of the proposed reconfiguration scheme. To demonstrate this attribute, a Structural Pilot Model ${ }^{9}$ is utilized to as part of a pilot-in-the-loop tracking task with the pilot dynamics are based upon the undamaged "effective vehicle" (aircraft plus control system). The Structural Model is shown in Figure 4. An interactive computer program $^{10}$ is used to determine the pilot model. This program can also be used in assessing the performance of the damaged vehicle with and without reconfiguration. Actuator dynamics including amplitude and rate limits are included in the simulation. In addition, the program of Ref. 10 can be employed to predict handling qualities levels with the nominal, damaged and the reconfigured vehicle.

\section{System Design \\ Example}

For the purpose of demonstrating the reconfiguration technique a MIMO system will be analyzed. A simple model of the lateraldirectional dynamics of the NASA F-18 High Angle of Attack Research Vehicle (HARV) ${ }^{17}$ will be used to demonstrate the methodology. As shown in Fig. 5 the vehicle has redundant effectors for both roll control (differential tail (DT), aileron (AI), and roll thrust vector (RTV)) and sideslip control (rudder (RU) and yaw thrust vector (YTV)). The base-line controller design (PDT and RLDI) is obtained for an undamaged vehicle for the 18 flight conditions shown in Fig. 6. The flight condition chosen for the reconfiguration example is also indicated in Fig. 6. This flight condition is the most challenging for the control system because of the low dynamic pressure.

Figures 7.8 show the magnitude plots for the tracking transfer functions $p / p_{c}$ and $\beta / \beta_{c}$ for all 18 flight conditions, including random variations in the elements of the vehicle dynamic model (elements of the $\mathbf{A}$ and $\mathbf{B}$ state space matrices) of a maximum $\pm 20 \%$. The pilot-in-the-loop tracking task is shown in Fig. 9. Note that no pilot input in the sideslip loop is assumed, i..e., the task is "feet on the floor" for the pilot. The upper and lower tracking bounds on the $p / p_{c}$ 
magnitude plots were evaluated for handling qualities and PIO tendencies using the computer program of Ref. 10 . The handling qualities prediction is based upon the "handling qualities sensitivity function" (HQSF) defined as

$$
H Q S F=\frac{1}{K_{e}}\left|\frac{U_{M}}{C}(j \omega)\right|
$$

where $U_{M}$ and $C$ are two signals in the Structural Pilot Model shown in Fig. 4. The predicted handling qualities levels as defined on the Cooper-Harper rating scale of Fig. 10 are based - upon whether the HQSF penetrates specified bounds on a linear HQSF vs frequency plot. 9.10 Likewise PIO "levels" defined on the PIO Rating (PIOR) scale of Fig. 11 are also predicted by plotting the power spectral density of the signal $U_{M}$ when a command $C$ with a specified power spectral density is applied. 9,10 Figure 12 shows results for the upper and lower tracking $\mathrm{p} / \mathrm{p}_{\mathrm{c}}$ bounds indicating level 1 handling qualities with no PIO tendencies. Note that these predictions were based upon a linear vehicle model.

Figure 13 shows the RLDI in more detail. In Fig. 13, $\mathbf{K}$ is a control distribution matrix that distributes the two pseudo-control signals emanating from the dynamic inverter to the five actuators. $\mathbf{K}$ is implemented with only a single non-zero entry in any row. The non-zero element is proportional to the rate limit of the actuator that it affects. This definition allows the use of "software rate limiters" Is to improve the tracking performance of the nominal vehicle under actuator rate saturation if desired. These software limiters were not included in this study, however. $\mathbf{G}$ is the RLDI controller or dynamic inverter. The actuators in Fig. 13 exhibit the rate and amplitude limits shown in Table 1.

Simple anti-windup logic has been implemented in the PDT module for both cases to cope with actuator saturation in the nominal design. This logic was created in each channel by removing an integrator from the PDT module in each control channel and simply replacing it with a limiting integrator. The upper and lower limits of the limiting integrator were obtained by trial and error using the computer simulation and are given in Table 1.

Figure 14 is a detailed representation of the Adaptive Module called out in Fig. 13 and shows the proposed MIMO, modified, filtered- $\varepsilon$ algorithm to be utilized in the examples. Design parameters of the PDT module and the RLDI are given in Table 1 . As discussed in the preceeding, the plant inverse is approximate and is based upon the desired dynamics of the decoupled system (referred to as the "reference model" in Table 1). All parameters are shown in Table 1 . The pilot model is determined from the PDT/RLDI control structure in the roll loop for the undamaged aircraft. For an evaluation of tracking performance, a crossover frequency of $1.5 \mathrm{rad} / \mathrm{sec}$ was utilized in the pilot/vehicle tracking loop, a value representative of pilot/vehicle crossover frequency in tracking, e.g, Ref. 19.

Figure 15 illustrates the adaptive filters, F11, F12, F21, and F22, for the 2 by 2 MIMO system pertinent to the example. Each filter has the same structure as in Fig. 2 except that the error $\varepsilon_{k}$ is replaced by a corresponding filtered error (filtered- $\varepsilon$.) An input signal $x_{k}$ for each filter is just the corresponding command from the PDT module. Each filter has its own set of weights and each set and adaptation step size can be chosen independently for each filter element. The weight sets $W k 11, W k 12, W k 21$, and $W / 22$ belong to $F 11, F 12, F 21$, and $F 22$, respectively. For simplicity, the same number of weights and adaptation step size are utilized for all filters. Figure 16 shows the 2 by 2 MIMO linear combiner composed of $\mathrm{C} 11, \mathrm{C} 12, \mathrm{C} 21$, and $\mathrm{C} 22$. Selection of the number of weights $L+1$ was obtained here by trial and error. First an equal number of weights were chosen for each of the four channels $(\mathrm{C} 11-\mathrm{C} 22)$. The number of weights was chosen as a large number that would still allow reasonable computation times on the simulation computer (a desktop PC). Here, this meant $L+1=50$. The paramter $\mu$ was selected according to the convergence criterion for singleinput, single output (SISO) systems of Refs. 15 and 16 as

$$
1<\mu<\frac{1}{(L+1) E\left[i_{k}{ }^{2}\right]}
$$

Proof of convergence for MIMO systems has yet to be derived. The utility of the SISO criterion lies in the approximate decoupling afforded by the RLDI and PDT systems. In inequality (3), $E\left[i_{k}{ }^{2}\right]$ is the temporal average of the square of the input power into the filter element, e.g., the roll- 
rate or sideslip commands indicated in Figs. 15 and 16. This value was estimated in this application. It is typical to select $\mu$ to be less than one-tenth the upper value in inequality (3). An example of the detailed structure of a linear combiner is shown in Fig. 17.

Since four control channels are involved, four values of the parameter $\mu$ could be selected. However, no crosscoupling commands were involved, e.g., no $\beta / p_{c}$ and there was no $\beta_{c}$ in the $\beta$-loop. Inequality (3) would thus imply arbitrarily large values of $\mu$ for these channels.

- Instead, the $\mu$ value for the p-loop was used for all four channels.

\section{Computer Simulation of Pilot/Vehicle Performance}

For the majority of the flight conditions and failures simulated the basic RLDI/QFTdefined system was capable of providing acceptable performance without reconfiguration. However, one challenging flight condition and failure demonstrated the utility of the reconfiguration scheme. This occurred when YTV was reduced to only $10 \%$ effectiveness at a flight condition involving a trim angle of attack $(A O A)=29.7$ degrees, a Mach No. $=0.2$, an altitude $=10,000$ feet with an aggressive roll tracking task presented to the simulated pilot. The 10\% effectiveness implies that the "gain", rate and amplitude limits of the actuator are only $10 \%$ of the nominal values. The roll command to the pilot consists of a series of filtered steps of 5 sec duration and varying amplitude, with some commanded changes as large as $40 \mathrm{deg}$. The reconfiguration is initiated with a failure occurring at $t=0 \mathrm{sec}$. The number of weights and adaptation step size $(\mu)$ for each filter are 50 and $1 \times 10^{-6}$, respectively. For purposes of evaluating tracking performance, the pilot model given in Table 1 for the nominal vehicle was used for nominal, damaged and reconfigured vehicles. For handling qualities evaluations, the pilot model for the damaged and reconfigured vehicle was tuned to the altered vehicle dynamics as will be described.

The roll angle responses of the healthy (undamaged or nominal), damaged and reconfigured vehicles are plotted in Fig 18. Sideslip responses are compared in Fig. 19. Adaptive filter weight time histories are shown in Fig. 20. For comparison purposes, the ordinates of each of the plots in Fig. 20 have been identically scaled. The shaded portions of the figure are actually the time histories of 49 of the weights in the case of Wk11 and Wk22 and all 50 weights in case of Wk12 and Wk21. As can be seen from Fig. 20, filter adaptation converges in approximately 20 secs. Of considerable importance is the fact that the reconfiguration logic operated in the presence of significant nonlinearities, both from the anti-windup integrators and the rate limited actuators.

\section{Prediction of Handling Qualities and PIO Susceptibility \\ The handling qualities and PIO} prediction methodology of Refs. 9 and 10 were next applied to the healthy, damaged and reconfigured vehicles. It should be emphasized that the latter evaluation was made on the reconfigured vehicle, but not on the vehicle during reconfiguration. The implementation of the LMS filter as part of the flight control system made it cumbersome to calculate of the $p / p_{c}$ transfer function needed for the pilot modeling technique of Refs. 9 and 10. This necessitated an identification of the $p / p_{c}$ transfer function for the damaged and reconfigured vehicles. This was accomplished by fitting a transfer function to the $\mathrm{p} / \mathrm{p}_{\mathrm{c}}$ Bode plot derived from a Fast Fourier Transform identification technique. Figure 21 shows the results for the reconfigured vehicle. The technique of Refs. 9 and 10 also requires a crossover frequency of $2.0 \mathrm{rad} / \mathrm{sec}$ the tracking loop being investigated. This was not achievable with the damaged vehicle, as instability resulted. This is synonymous with predicted level 3 handling qualities. For the handling qualities and PIO analysis for both the damaged and reconfigured vehicles, the pilot model was changed from that indicated in Table 1. This was an absolute necessity since the methodology of Refs. 9 and 10 were predicated upon a pilot model properly tuned to the vehicle dynamics at hand.

Figures 22-23 show the predicted handling qualities and PIO levels for the nominal and damaged vehicles using the program of Ref. 10. The nominal vehicle shows a violation of the level I boundary. This is attributable to the aggressive nature of the roll attitude command of Fig. 18. Note that the reconfigured vehicle has retained predicted level 1 handling qualities with minimal PIO tendencies. Figure 24-25 show the amplitude and rate limiting that was occurring during and after reconfiguration as compared to 
that of the damaged vehicle. This limiting is attributable both to the challenging nature of the flight condition, and to the reconfigurable control scheme attempting to recapture performance lost due to the failure in the thrust vectoring nozzle. The nonlinearities did not, however, inhibit the reconfiguration.

\section{Conclusions \\ A methodology for MIMO} reconfigurable flight control design utilizing a robust controller and adaptive filter has been proposed. The demonstration of the proposed system shows significant improvement in tracking performance as compared to the same vehicle without reconfiguration in a challenging example from one of the 18 flight conditions in the flight envelope for which the nominal system was designed. The reconfiguration was characterized by fast adaptation times during which the simulated pilot retained control. Application to a system with nonlinear effects supports the utility of the proposed concept.

\section{Acknowledgment}

This research was supported by grants from NASA Dryden Flight Research Center and NASA Langley Research Center. The grant technical managers were John Burken and Bart Bacon at NASA Dryden and NASA Langley, respectively.

\section{References}

'Ostroff, A. J., and Hueshcen, R.M., "Investigation of Control Law Reconfiguration to Accommodate a Control Element Failure on a Commercial Aircraft," Proceeding of the 1984 American Control Conference, San Diego, CA, June, 1984

${ }^{2}$ Eslinger, R.A., and Chandler, P.R., "Self-Repairing Flight Control System Program Overview," Proceeding of IEEE National Aerospace and Electronics Conference, 1988, pp. 504-511

${ }^{3}$ Chandler, P.R., "Issues in Flight Control Design for Robustness to Failures and Damages," Proceeding of IEEE International Conference on Control Applications, Jenusalem, Israel, paper WP-2-7, 1989

"Kim, B.S., and Calise, A.J., "Nonlinear Flight Control Using Neural Networks," Journal of Guidance, Control, and Dynamics, Vol.20, No. 1, 1997, pp. 26-33

'Bodson, M., and J. Groszkiewicz, "Multivariable Adaptive Algorithms for
Reconfigurable Flight Control," IEEE Transactions on Control Systems Technology, Vol.5, No.2, 1997, pp. 217-229

${ }^{6}$ Hess, R.A., Siwakosit, W., and Chung. J., "Accommodating A Class of Actuator Failures in a Flight Control System, Journal of Guidance, Control, and Dynamics, to appear.

${ }^{7}$ Burken, J, Lu, P. and Wu, Z, "Reconfigurable Flight Control Designs with Application to the X-33 Vehicle, AIAA Paper No. 99.4134, AIAA Guidance, Navigation and Control Conference, 9-11 Aug., 1999, Portland, OR.

'Hess, R. A., and McLean, C., "Development of a Design Methodology for Reconfigurable Flight Control Systems," AIAA Paper No. 99-4134, AIAA Guidance, Navigation and Control Conference, 9.11 Aug., 199, Portland, Or.

'Hess, R.A., "A Unified Theory for Aircraft Handling Qualities and Adverse PilotVehicle Coupling," Journal of Guidance, Control, and Dynamics, Vol. 20, No.6, 1997, pp. 1141-1148.

${ }^{10}$ Zeyada, Y., Hess, R.A., "PVD Pilot/Vehicle Dynamics NonLimers - An Interactive Computer Program for Modeling the Human in Single-Axis Linear and Nonlinear Tracking Tasks," Dept. of Mechanical and Aeronautical Engineering, University of California, Davis, 1998.

"Henderson, D.K. and Hess, R.A., "Approximations for Quantitative Feedback Theory Designs," Journal of Guidance, Control, and Dynamics, Vol.20, No.4, 1996, pp. 828-831

${ }^{12}$ Snell, A., "Decoupling Control Design with Applications to Flight," Journal of Guidanc, Control, and Dynamics, Vol.21, No.4, 1998, pp. 647-655

${ }^{13}$ Siwakosit, W., Snell, S. A., and Hess, R.A., "Robust Flight Control Design with Handling Qualities Constraints Using Scheduled Linear Dynamic Inversion and Loop-Shaping," IEEE Transactions on Control Systems Technology, Vol. 8, No. 3, 2000, pp. 483-494.

"Widrow, B., and Stearns, S.D., Adaptive Signal Processing, Prentice Hall, N.J., 1985

15Widrow, B., and Wallach, E., Adaptive Inverse Control, Prenctice Hall, N.J., 1996.

${ }^{16}$ Siwakosit, W., "Robust and Reconfigurable Flight Control Design," Ph.D. Dissertation, Dept. of Mechanical and Aeronautical Engineering, University of California, Davis, Sept., 2000. 
${ }^{17}$ Adams, R.J., Buffington, J.M., Sparks, A.G., and Banda, S.S., "An Introduction to Multivariable Flight Control System Design," WL-TR-92-3110, Wright Laboratory, WPAFB, $\mathrm{OH}, 1992$

"Snell, S.A., and Hess, R. A., "Robust Decoupled, Flight Control Design in with Rate Saturating Actuators," Journal of Guidance,
Control, and Dynamics, Vol. 21, No. 3, 1998, pp. 361-367.

${ }^{19}$ Mitchell, D. G., Aponso, B. L., and D. H. "Effects of Cockpit Lateral Stick Characteristics on Handling Qualities and Pilot Dynamics," NASA CR 4443, June, 1992.

\section{Table 1 Vehicle, Pilot, and Control System Parameters}

$$
\begin{gathered}
\text { Aircraft Linearized Model } \\
\begin{aligned}
\dot{\mathbf{x}}=\mathbf{A x}+\mathbf{B \Delta} \\
\mathbf{y}=\mathbf{C x}+\mathbf{D \Delta}
\end{aligned} \quad \text { where } \quad \mathrm{x}(t)=\left[\begin{array}{c}
\beta(t) \\
p(t) \\
r(t)
\end{array}\right], \Delta(t)=\left[\begin{array}{c}
\delta_{D T} \\
\delta_{A t} \\
\delta_{R U} \\
\delta_{R T V} \\
\delta_{r T V}
\end{array}\right] \\
\beta=\text { angle of sideslip, deg; } \quad \mathrm{p}=\text { roll rate, deg/sec; } \quad \mathrm{r}=\text { yaw rate, deg/sec } \\
\delta_{\mathrm{DT}}=\text { differential tail (DT), deg; } \delta_{\mathrm{AI}}=\text { aileron }(\mathrm{AI}), \operatorname{deg} ; \quad \delta_{\mathrm{RU}}=\text { rudder }(\mathrm{RU}), \text { deg } \\
\delta_{\mathrm{RTV}}=\text { roll thrust vector angle (RTV), deg; } \delta_{\mathrm{YTV}}=\text { yaw thrust vector angle }(\mathrm{YTV}) \text {, deg }
\end{gathered}
$$

Example: (angle of attack $=29.73 \mathrm{deg}$, mach $=0.2$, altitude $=10,000$ feet

$$
\mathbf{A}=\left[\begin{array}{ccc}
-0.059 & 0.496 & -0.868 \\
-5.513 & -0.939 & 0.665 \\
0.068 & 0.026 & -0.104
\end{array}\right] \quad \mathbf{B}=\left[\begin{array}{ccccc}
0.006 & 0.006 & 0.004 & 0 & 0.090 \\
1.879 & 1.328 & 0.029 & 0.675 & 0.217 \\
-0.109 & -0.096 & -0.084 & 0.007 & -2.974
\end{array}\right]
$$

DT: $\quad \frac{30^{2}}{s^{2}+42.4 s+30^{2}} \quad$ amplitude limit $=+1-17.5 \mathrm{deg}, \quad$ rate limit $=+1.60 \mathrm{deg} / \mathrm{sec}$

AI: $\quad \frac{75^{2}}{s^{2}+88.5 s+7 s^{2}}$ amplitude limit $=+/-27.5 \mathrm{deg}$, rate limit $=+/-100 \mathrm{deg} / \mathrm{sec}$

RU: $\quad \frac{72^{2}}{s^{2}+99.4 s+72^{2}} \quad$ amplitude limit $=+1-30 \mathrm{deg}, \quad$ rate limit $=+/-100 \mathrm{deg} / \mathrm{sec}$

RTV $/ Y T V: \frac{20^{2}}{s^{2}+24 s+20^{2}}$ amplitude limit $=+/-30 \mathrm{deg}, \quad$ rate limit $=+/-60 \mathrm{deg} / \mathrm{sec}$

\section{PDT Controller}

$G_{\text {PDT }}=\left[\begin{array}{cc}\frac{197.33(s+5.15)(s+0.97)\left(s^{2}+22.30 s+355.4\right)\left(s^{2}+102.70 s+5070\right)}{s(s+58.96)^{3}(s+4.38)\left(s^{2}+24.74 s+509.90\right)} & 0 \\ 0 & \frac{216.16(s+0.97)\left(s^{2}+43.05 s+896.30\right)\left(s^{2}+87.25 s+5516.00\right)}{s(s+58.96)^{3}\left(s^{2}+44.67 s+1266.00\right)}\end{array}\right]$

Anti-Windup limits at an integrator at each control channel $=+/-20(\mathrm{deg} / \mathrm{sec}$ or deg)

7

American Institute of Aeronautics and Astronautics 
Table 1, cont'd

$$
\begin{gathered}
\underline{\text { RLDI Controller }} \\
\mathbf{G}=\left[\left(\mathbf{A}_{\mathbf{G}}-\mathbf{H}_{\mathbf{o b s}}\right),\left[\mathbf{B}_{\mathbf{G}} \mathbf{H}_{\mathbf{o b s}}\right], \mathbf{C}_{\mathbf{G}},\left[\mathbf{D}_{\mathbf{G}}\left[\begin{array}{lll}
0 & 0 & 0 \\
0 & 0 & 0
\end{array}\right]\right]\right. \\
\mathbf{A}_{\mathbf{G}}=\left(\mathbf{A}-\mathbf{B K E}_{\mathbf{R}}^{-1} \mathbf{F}\right), \mathbf{B}_{\mathbf{G}}=\mathbf{B K E}_{\mathbf{R}}^{-1}, \mathbf{C}_{\mathbf{G}}=-\mathbf{E}_{\mathbf{R}}^{-1} \mathbf{F}, \mathbf{D}_{\mathbf{G}}=\mathbf{E}_{\mathbf{R}}^{-1} \\
\text { reference model for each channel }=\frac{1}{\mathrm{~S}+1} \\
\mathbf{E}=\mathbf{C B K}, \mathbf{F}=\mathbf{C}+\mathbf{C A}_{;} \mathbf{E}_{\mathbf{R}}^{-1}=\text { right inverse of } \mathbf{E} \\
\mathbf{H}_{\mathbf{o b s}}=\left[\begin{array}{lll}
1 & 0 & 0 \\
0 & 1 & 0 \\
0 & 0 & 5
\end{array}\right] \quad \mathbf{K}=\left[\begin{array}{cc}
0 & 0.6 \\
0 & 1 \\
1 & 0 \\
0 & 0.6 \\
0.6 & 0
\end{array}\right]
\end{gathered}
$$

Pilot Model for Nominal Vehicle*(for tracking with nominal, damaged and reconfigured vehicle)

$$
\text { Pilot }=\frac{3.139 \cdot 10^{5}}{\left(s^{2}+7.027 s+165.64\right)\left(s^{2}+41.97 s+754.6\right)} \frac{\text { units displacement }}{\text { rad }}
$$

Pilot Model for Reconfigured Vehicle* (for handling qualities evaluation)

$$
\text { Pilot }=\frac{2.545 \cdot 10^{5} e^{-0.2 s}}{\left(s^{2}+4.1 s+197.7\right)\left(s^{2}+45 s+837.7\right)} \frac{\text { units displacement }}{\text { rad }}
$$

*Includes loop closure about force/feel system given by

$$
Y_{F S}=\frac{25^{2}}{s^{2}+35 s+25^{2}} \quad \frac{\text { units displacment }}{\text { units force }}
$$

\section{Adaptive Filter}

50 weights in each filter, adaptation step size $\mu=1 \times 10^{-6}$, sampling frequency $=50 \mathrm{~Hz}$

$$
\text { reference model for filtered }-\varepsilon \text { algorithm }=\left[\begin{array}{cc}
\frac{1}{(s+1)} & 0 \\
0 & \frac{1}{(s+1)}
\end{array}\right]
$$

8 


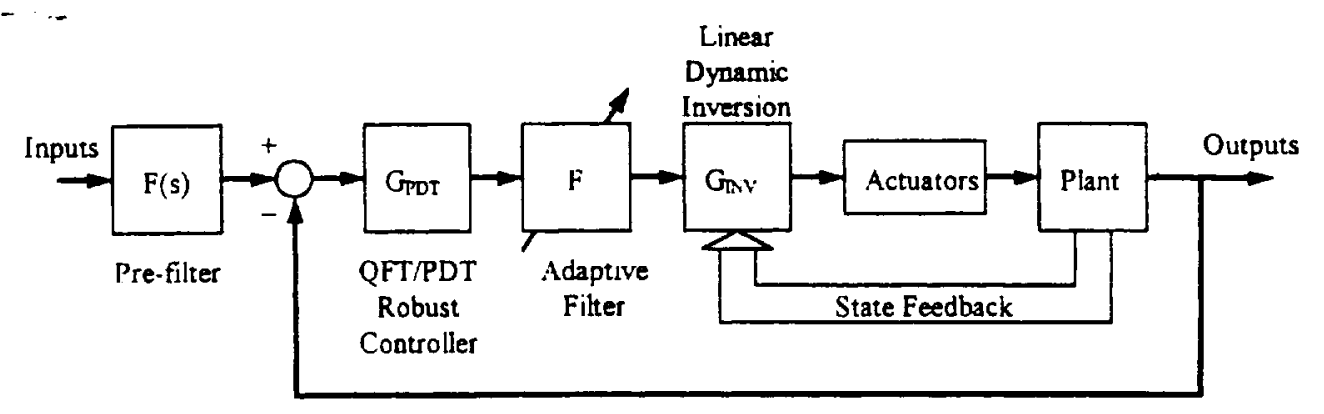

Figure I Reconfigurable flight control scheme

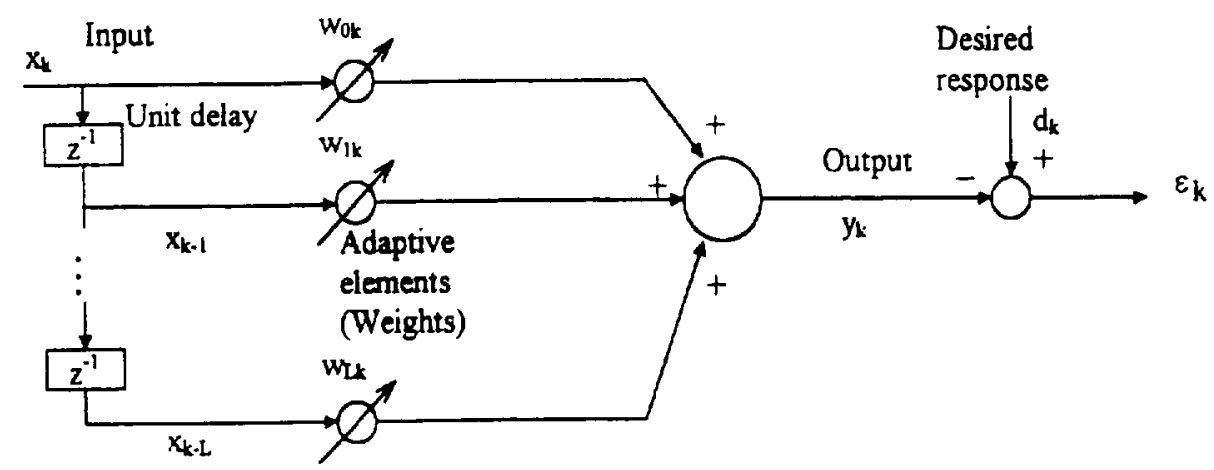

Figure 2 Adaptive filter in transversal filter form 


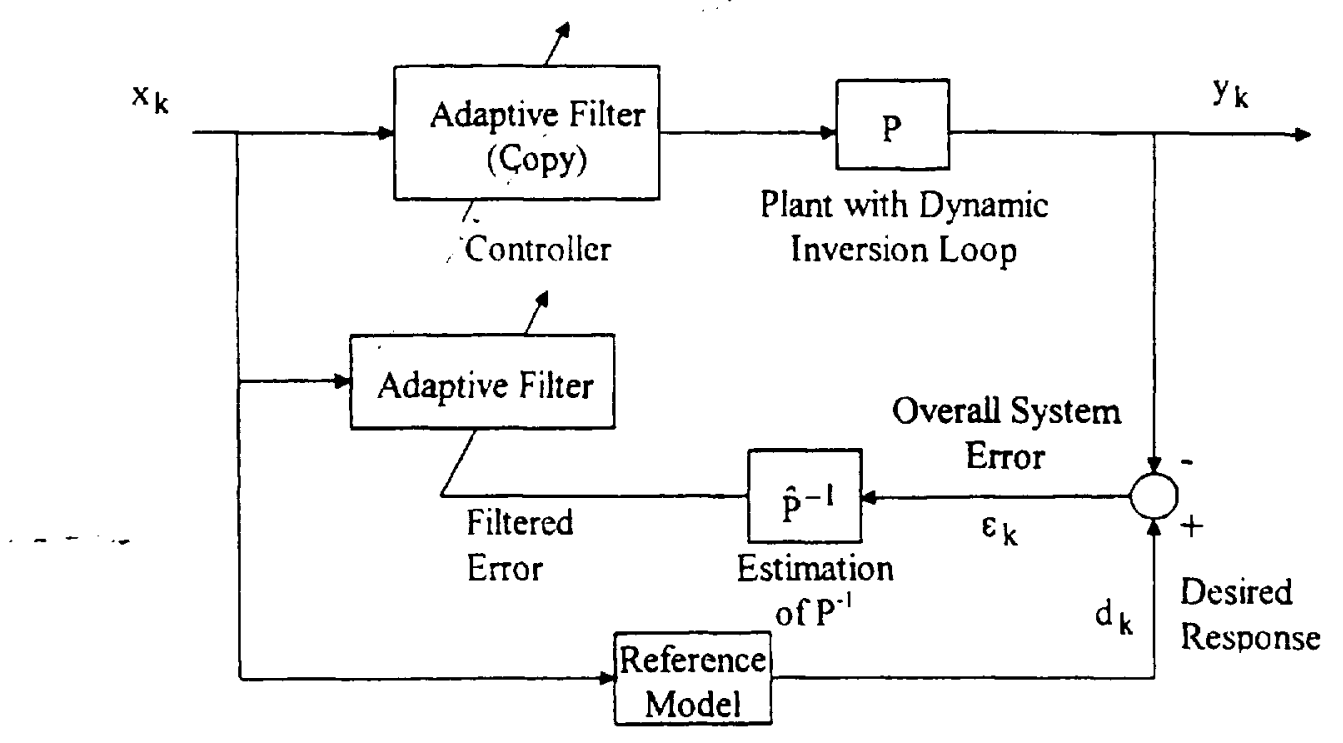

Figure 3 Filtered-LMS algorithm

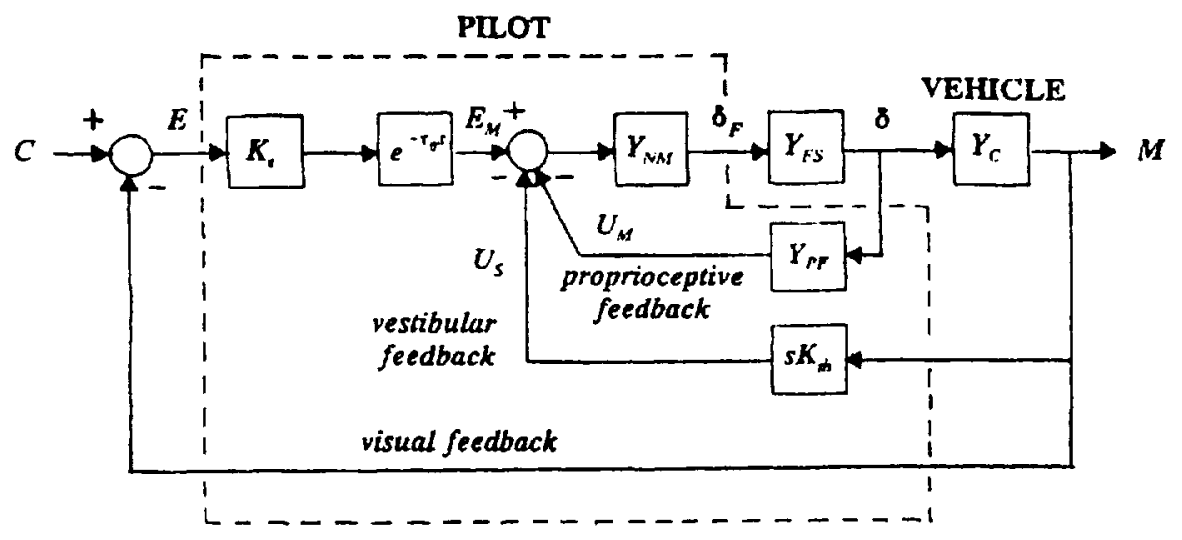

Figure 4 Structural model of human pilot 


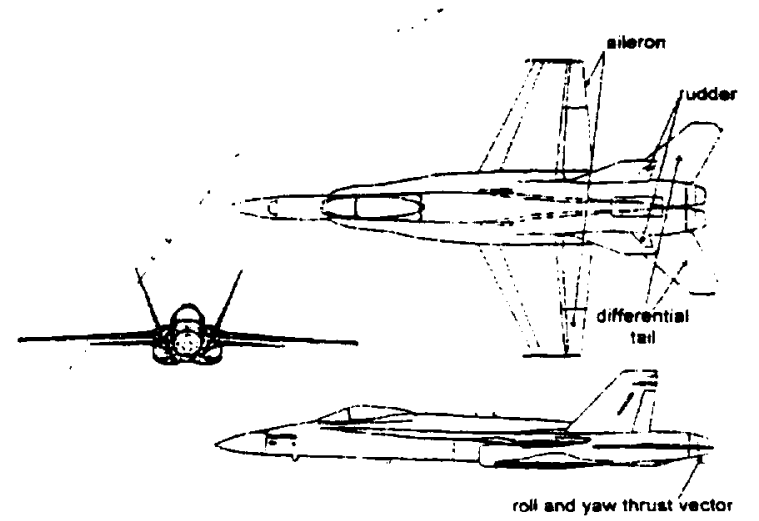

Figure 5 NASA HARV with lateral-directional control effectors

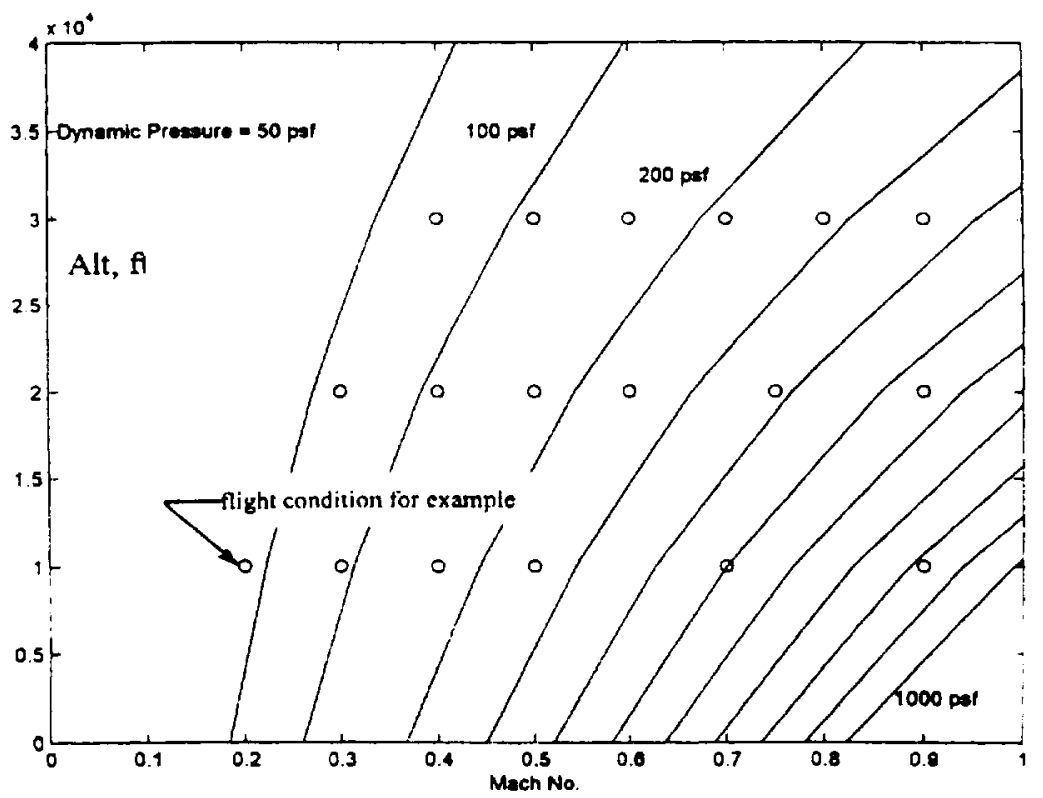

Figure 618 flight conditions used in design

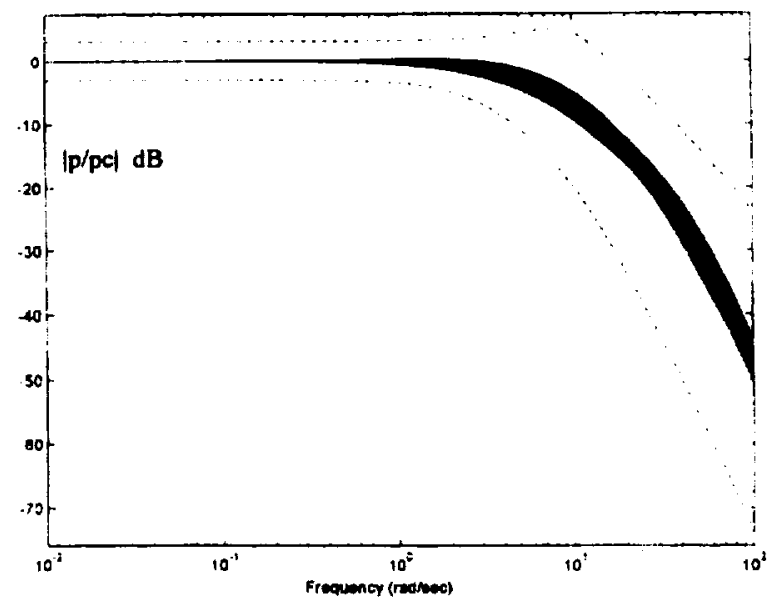

Figure 7 Bode plots for $p / p_{c}$ for all flight conditions with 20 model perturbations for each flight conditon 


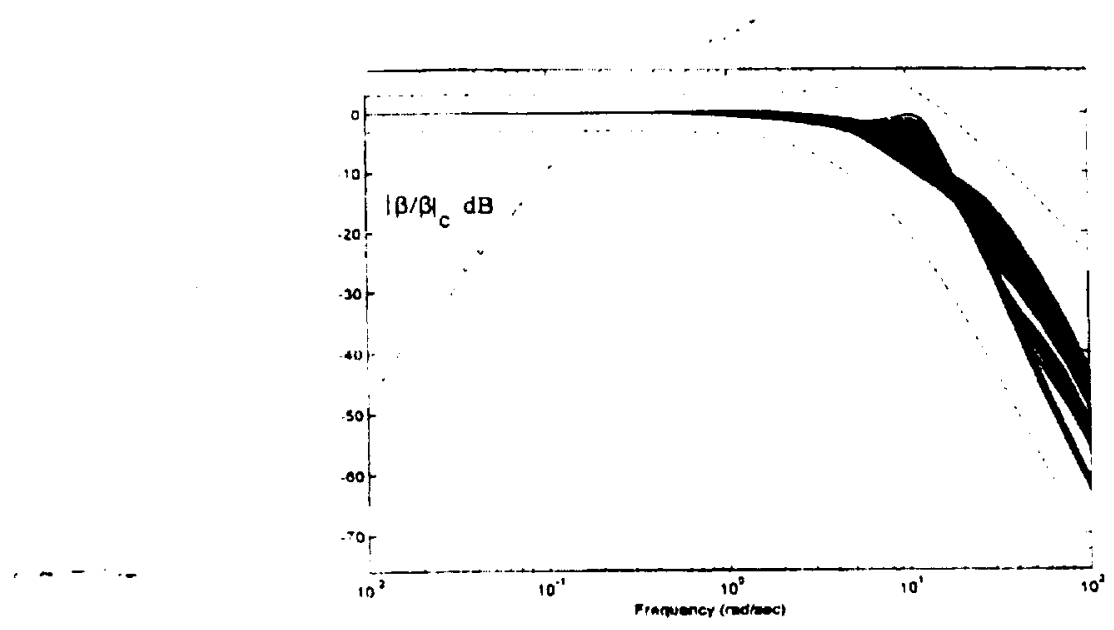

Figure 8 Bode plots for $\beta / \beta_{c}$ for all flight conditions with 20 model perturbations for each flight condition

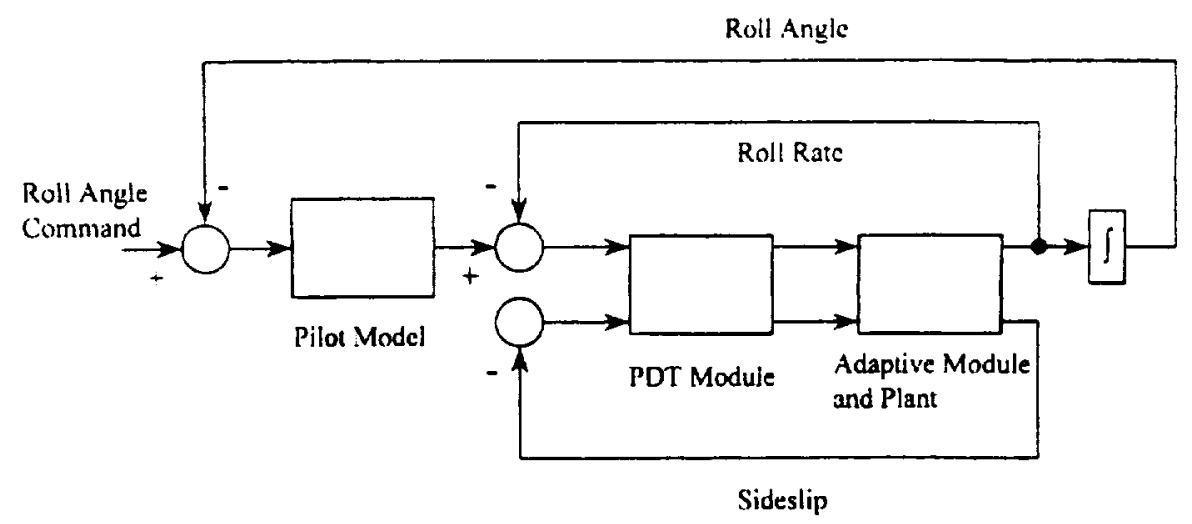

Figure 9 Block diagram of lateral-directional flight control system with pilot in the loop

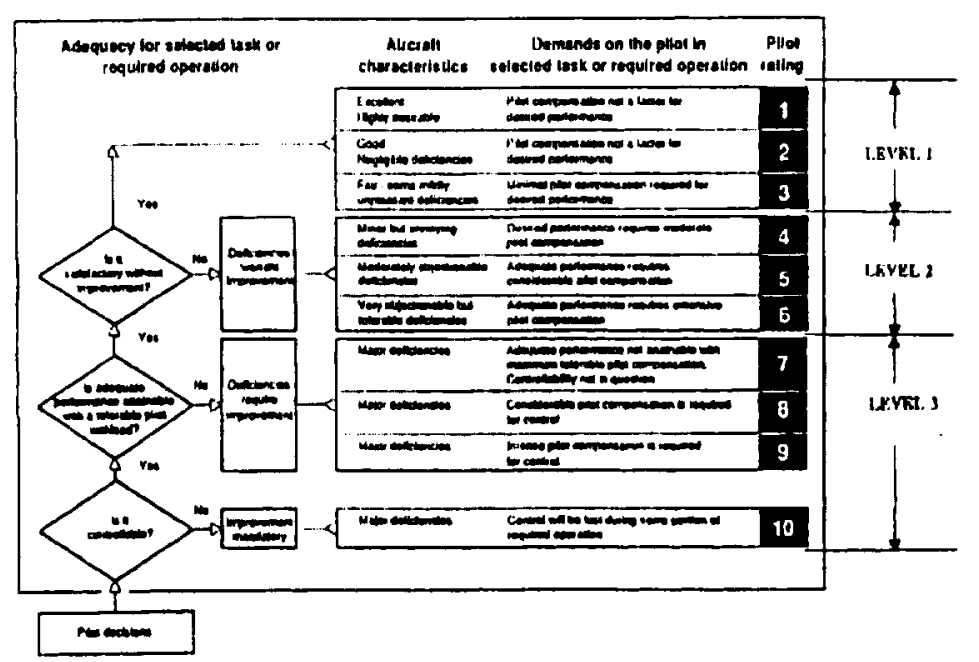

Figure 10 The Cooper-Harper handling qualities rating scale 


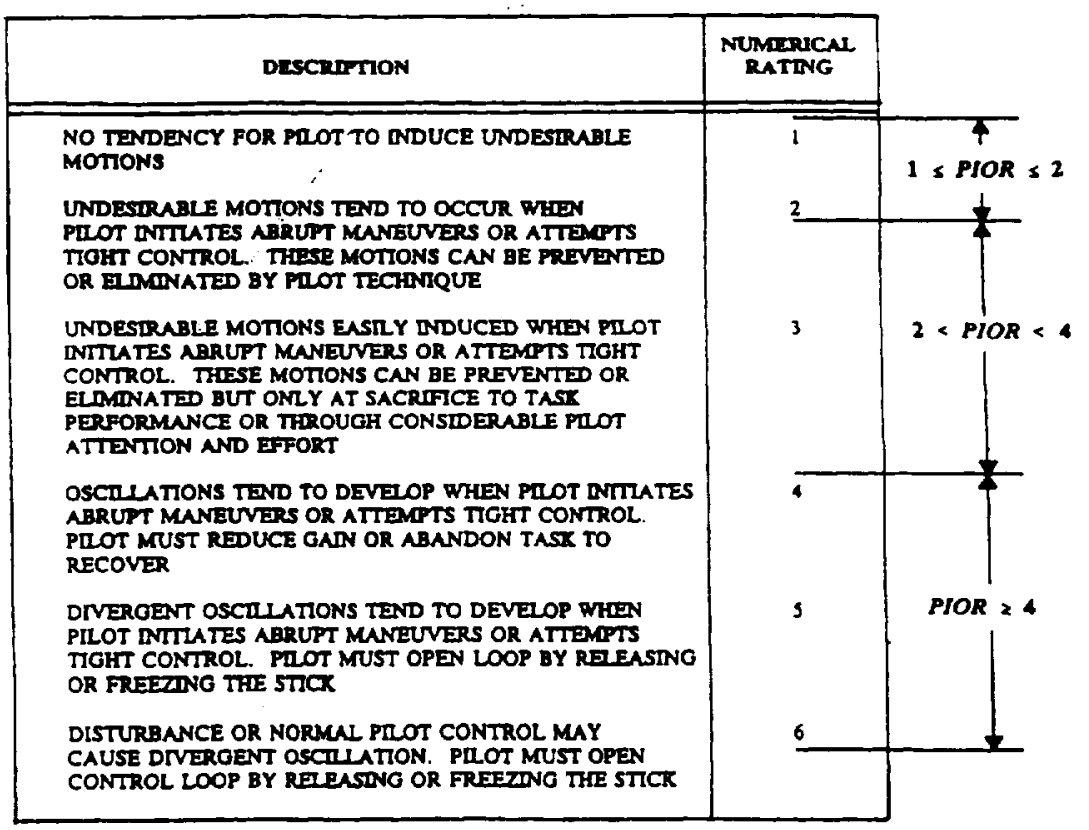

Figure 11 The pilot-induced oscillation rating scale
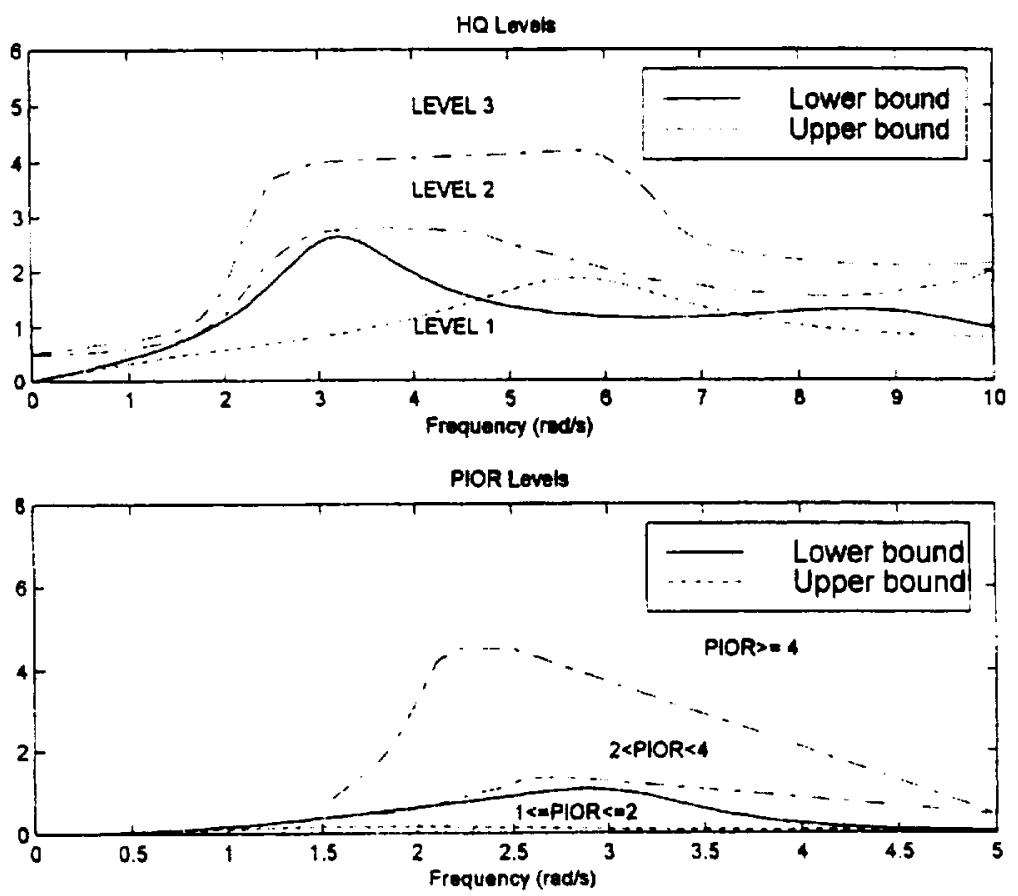

Figure 12 Structural model handling qualities and PIO prediction for $\mathrm{p} / \mathrm{p}_{\mathrm{c}}$ magnitude bounds from Fig. 7 


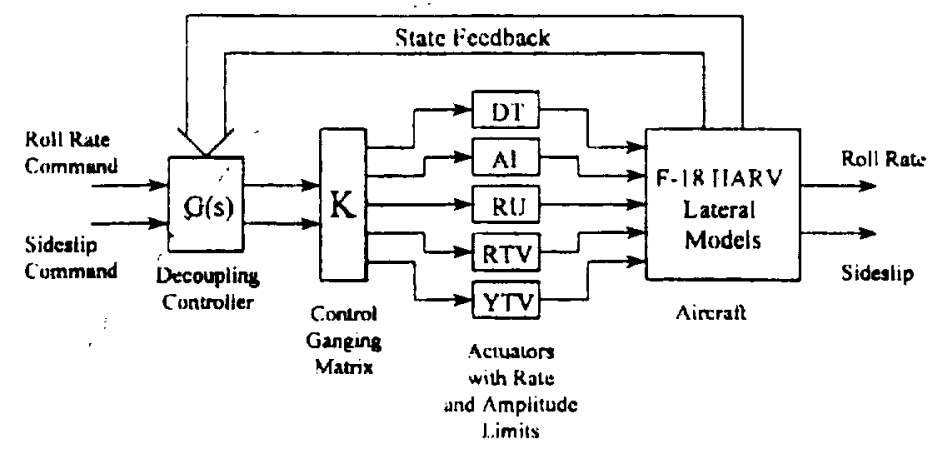

DIT = Differential Tail (Roll Control). AI - Aileron (Rull Control)

RU = Rudder (Yaw Conuol), RIV = Roll Ihrust Vector 1 Roll Control)

YTV $\approx$ Yuw Tlurust Vector (Yaw Cuntrol)

Figure 13 Decoupled control scheme for NASA HARV

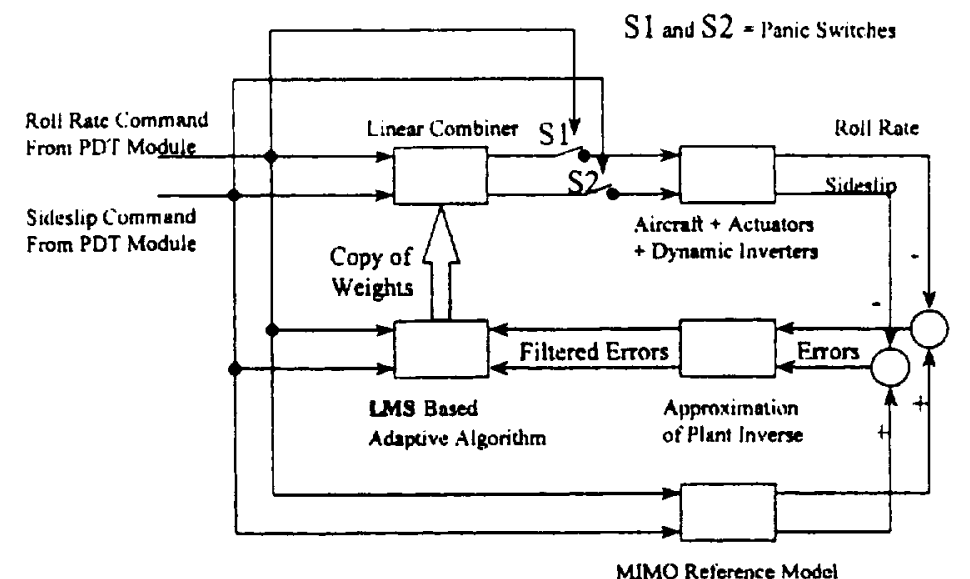

Figure 14 Adaptable module and plant using modified, filtered- $\varepsilon$ algorithm

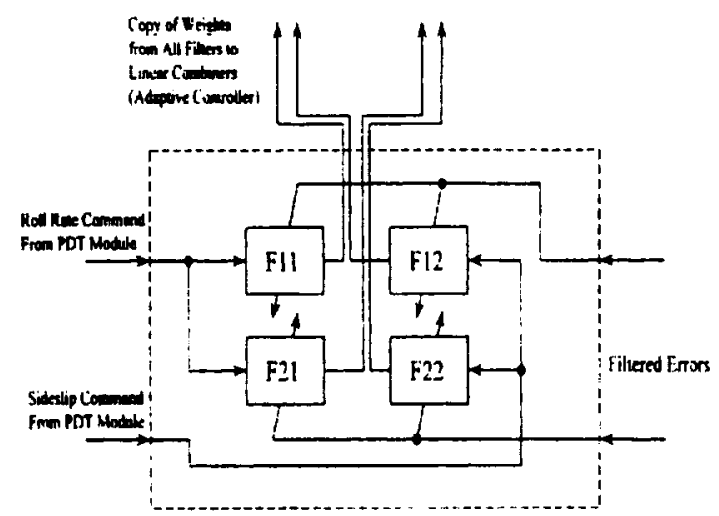

Figure 15 LMS algorithm-based adaptive filters 


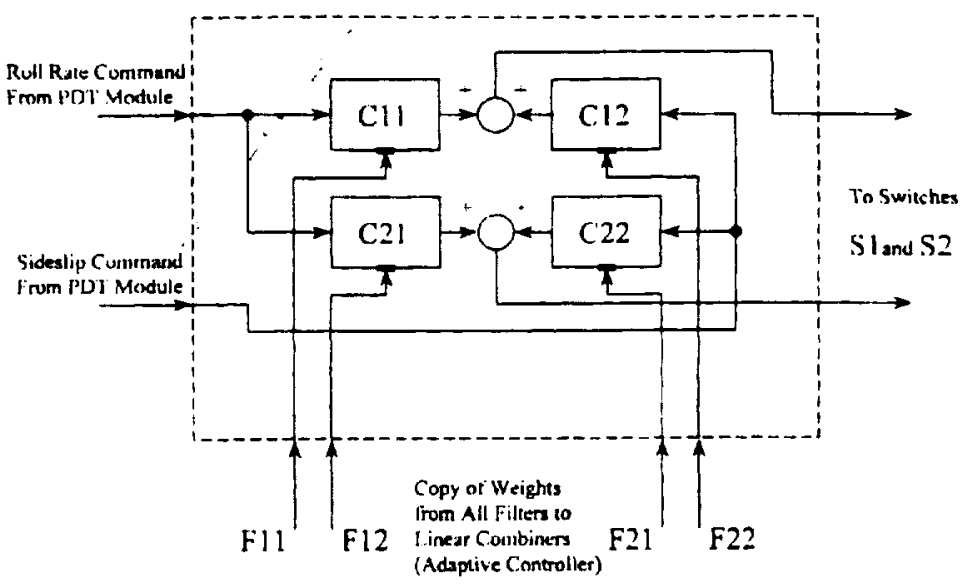

Figure 16 Linear combiners

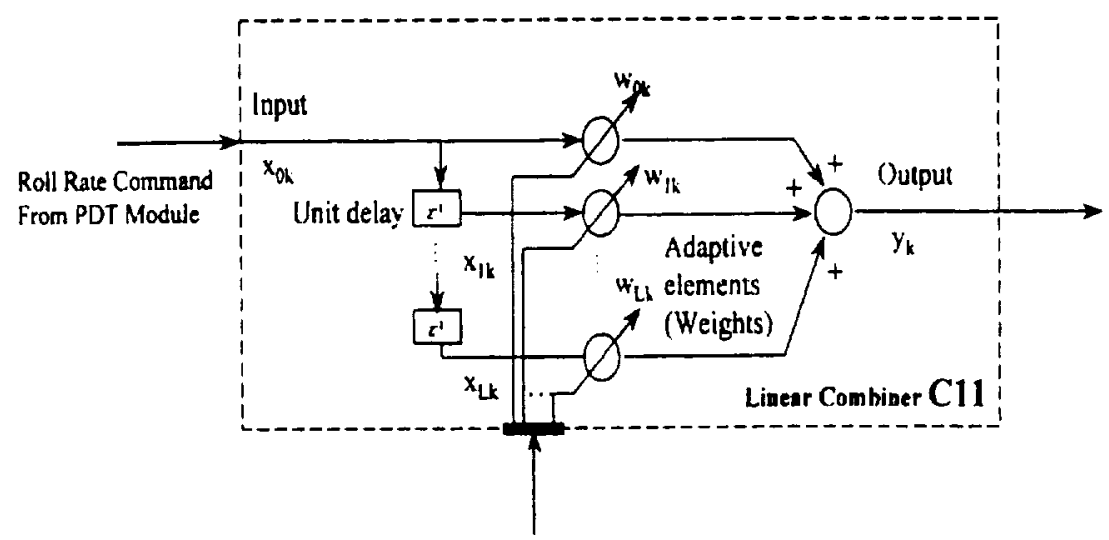

Copy of Weights from Filter F11

Figure 17 Detail of linear combiner $\mathrm{Cl1}$ 


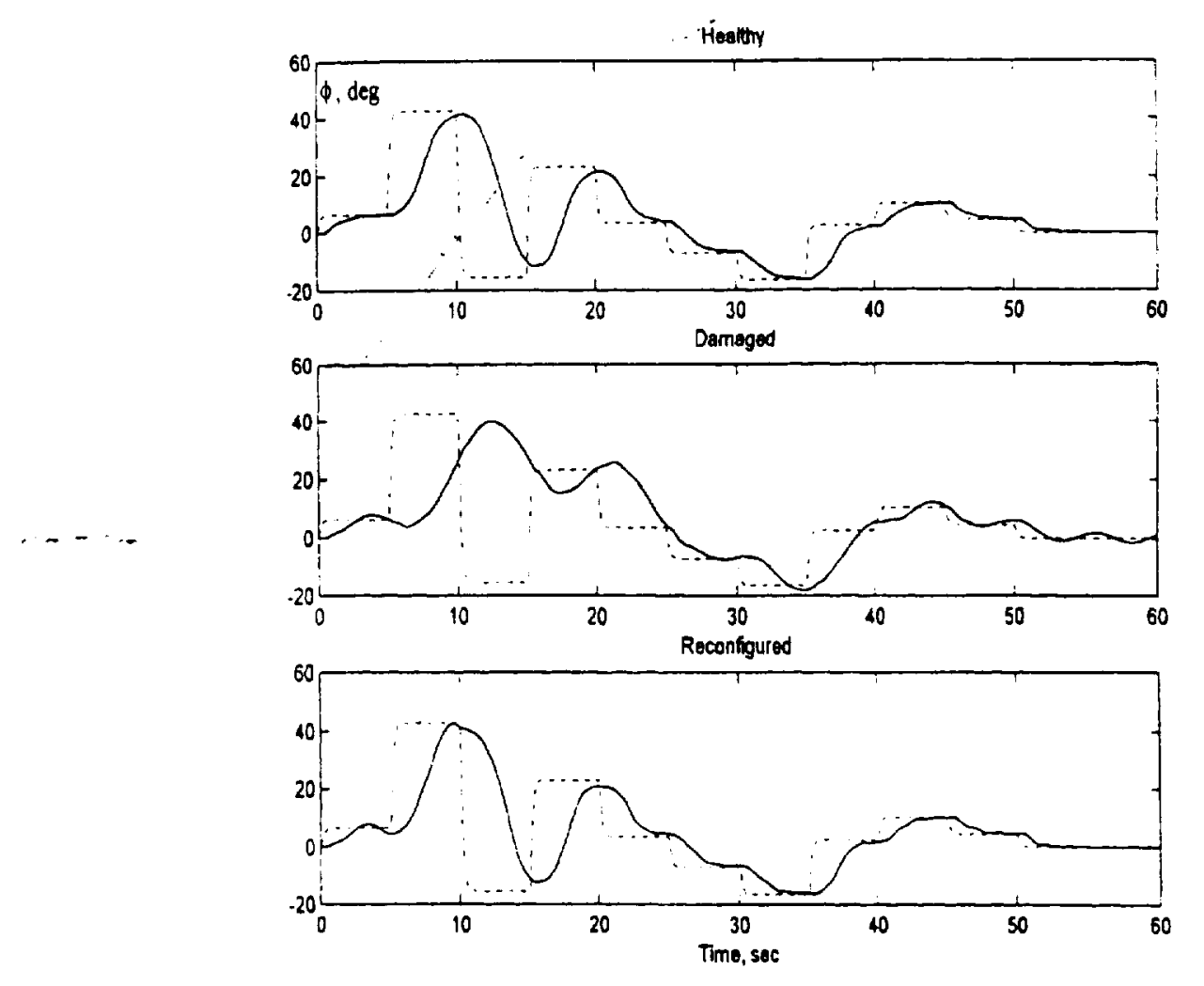

Figure 18 Roll tracking results for healthy, damaged, and reconfigured vehicle 

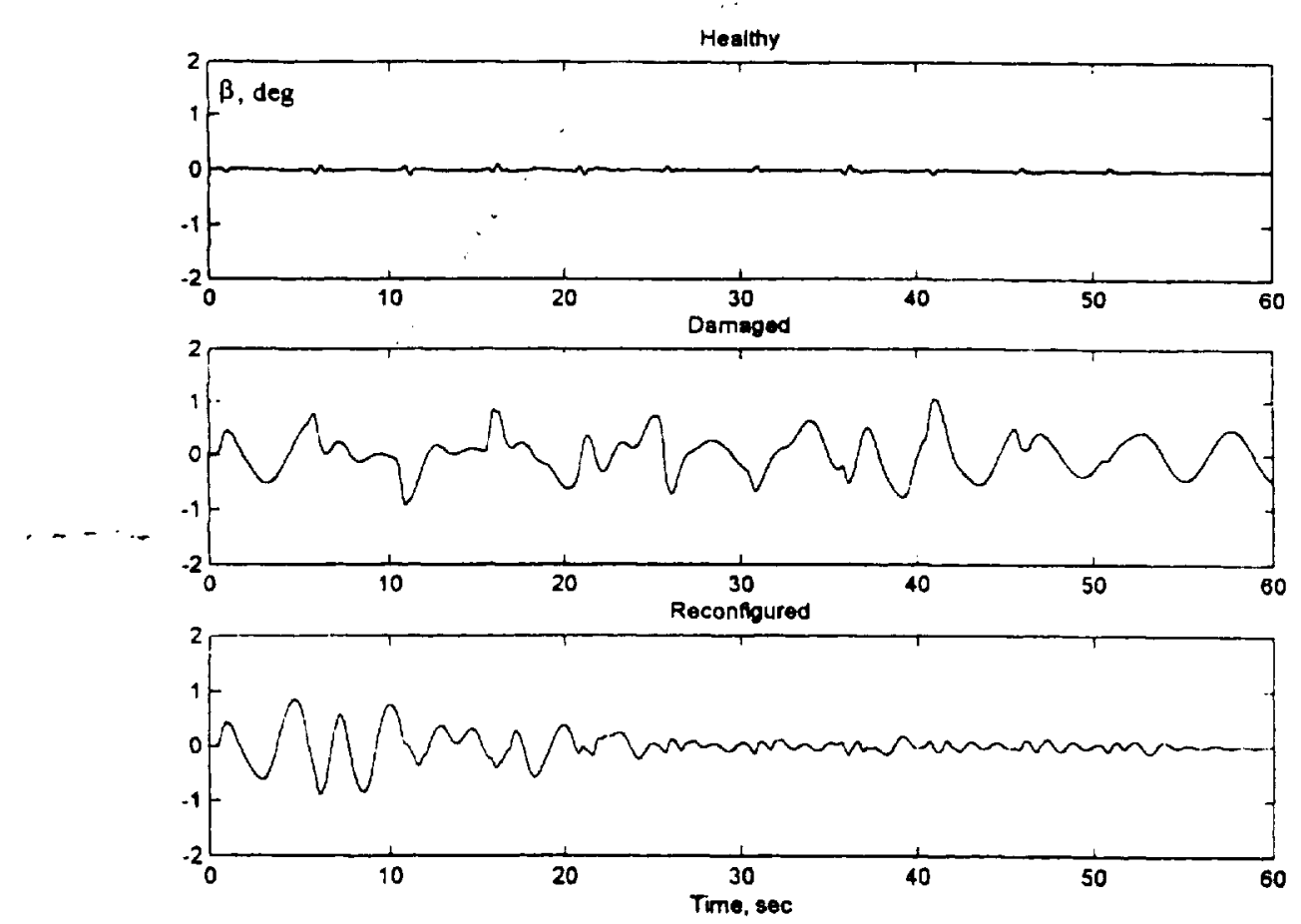

Figure 19 Sidelslip response results for healthy, damaged, and reconfigured vehicle
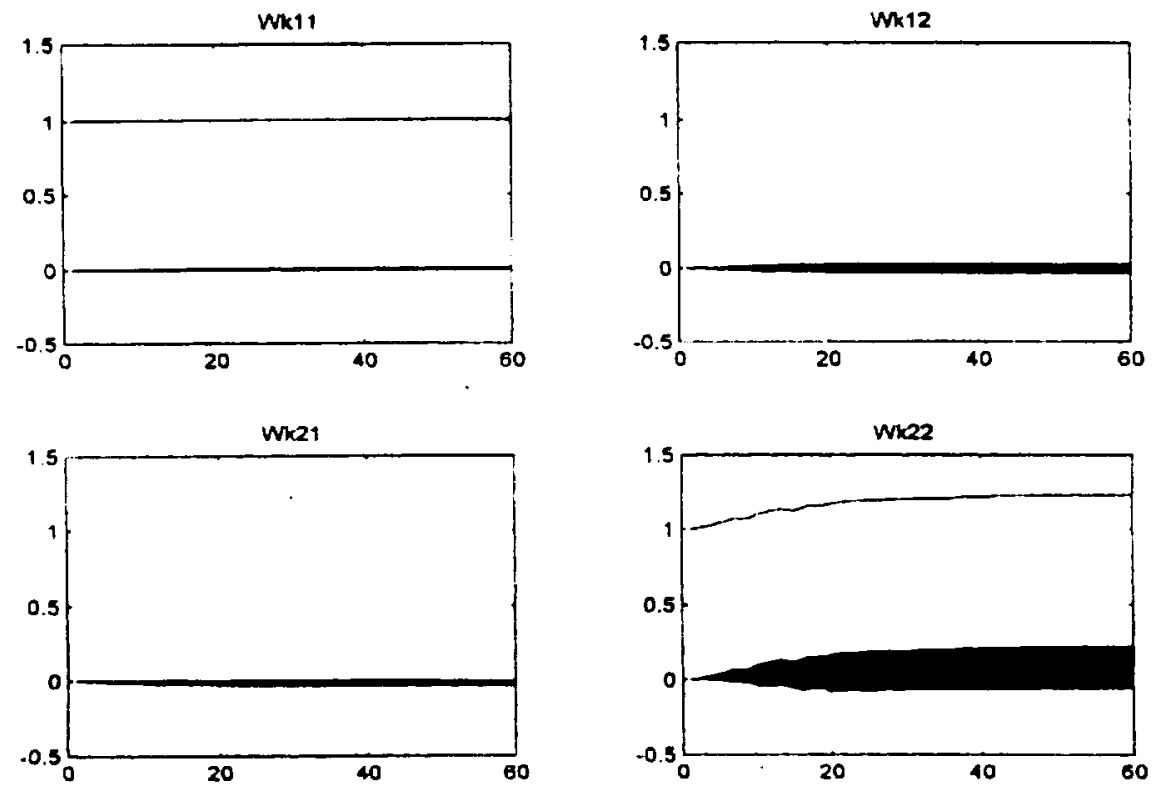

Figure 20 Filter weight time histories during reconfiguration

17 

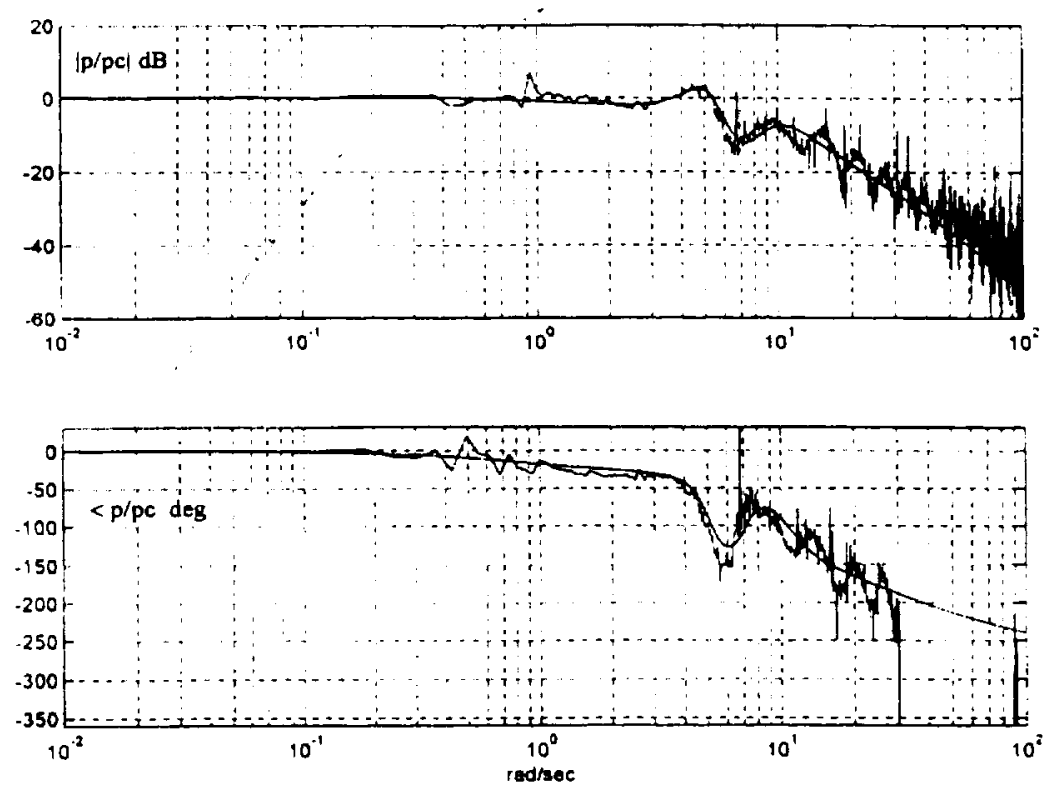

Figure 21 Bode plot of $p / p_{c}$ identification and fit after reconfiguration
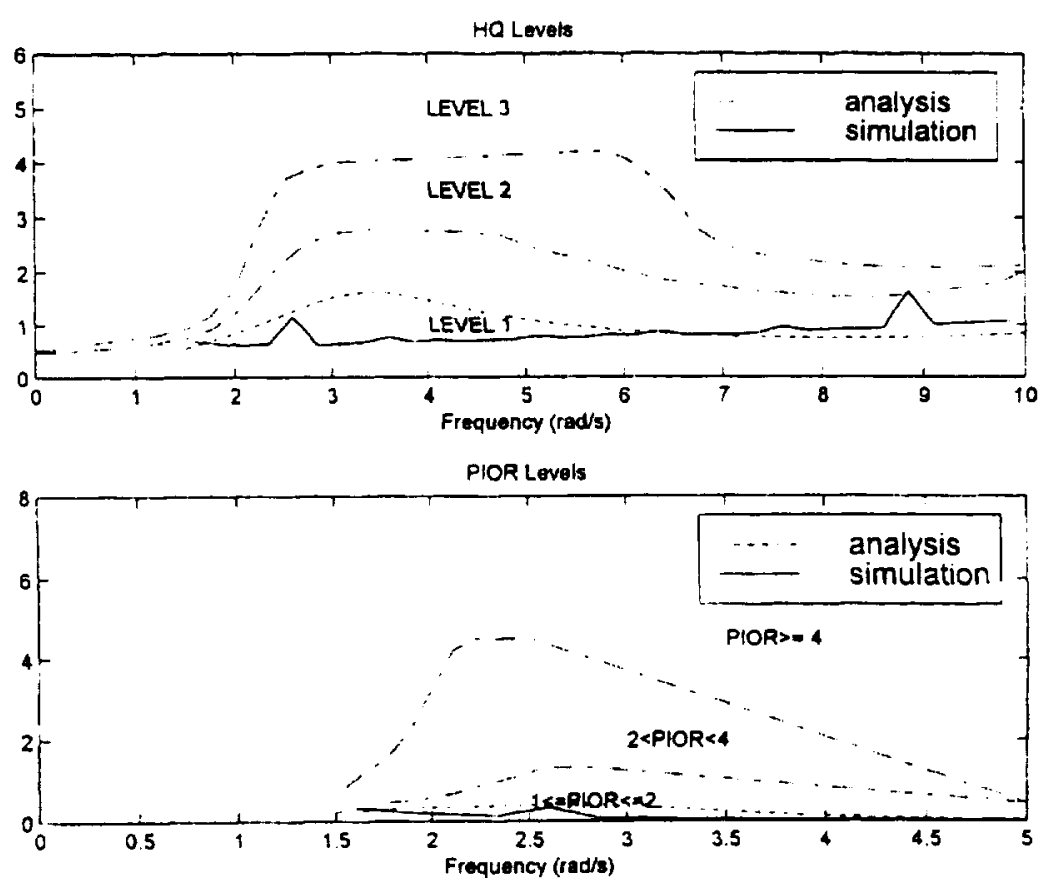

Figure 22 Structural model handling qualities and PIO prediction for nominal vehicle in tracking, "Analysis" refers to linear vehicle 

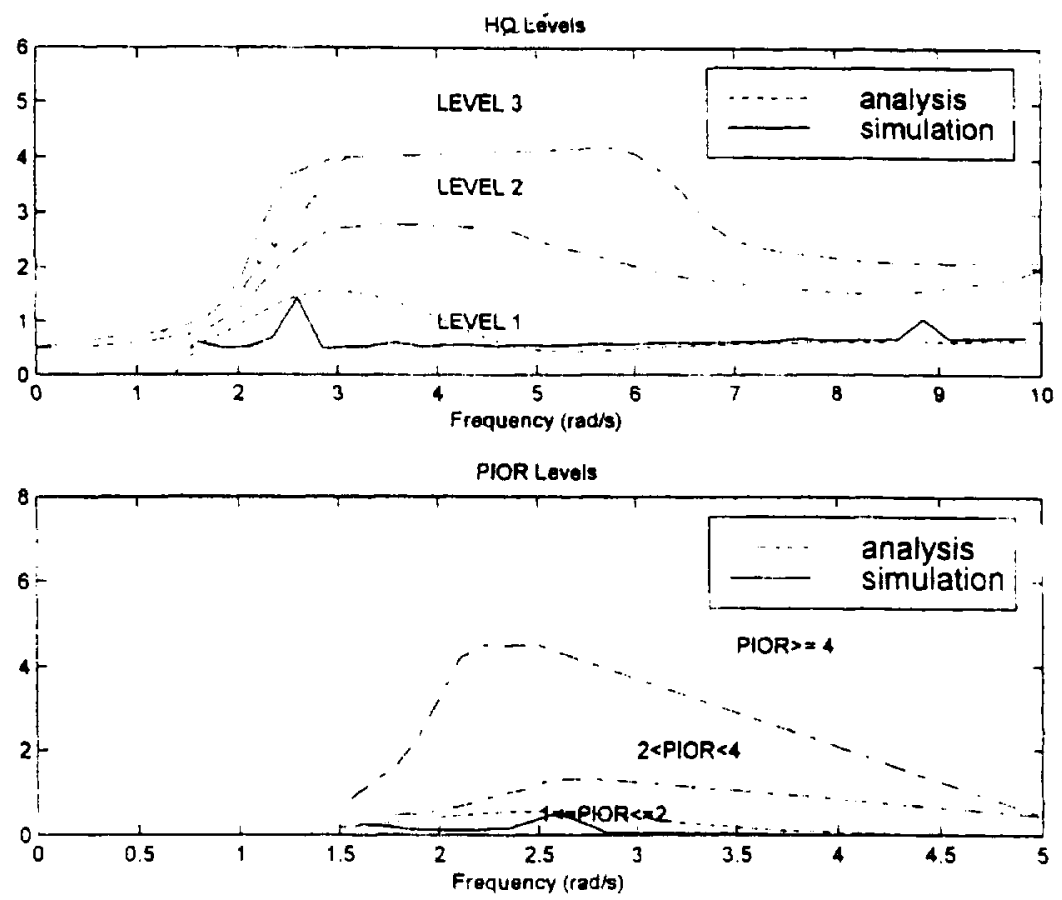

Figure 23 Structural model handling qualities and PIO prediction for reconfigured vehicle in tracking, "Analysis" refers to linear vehicle
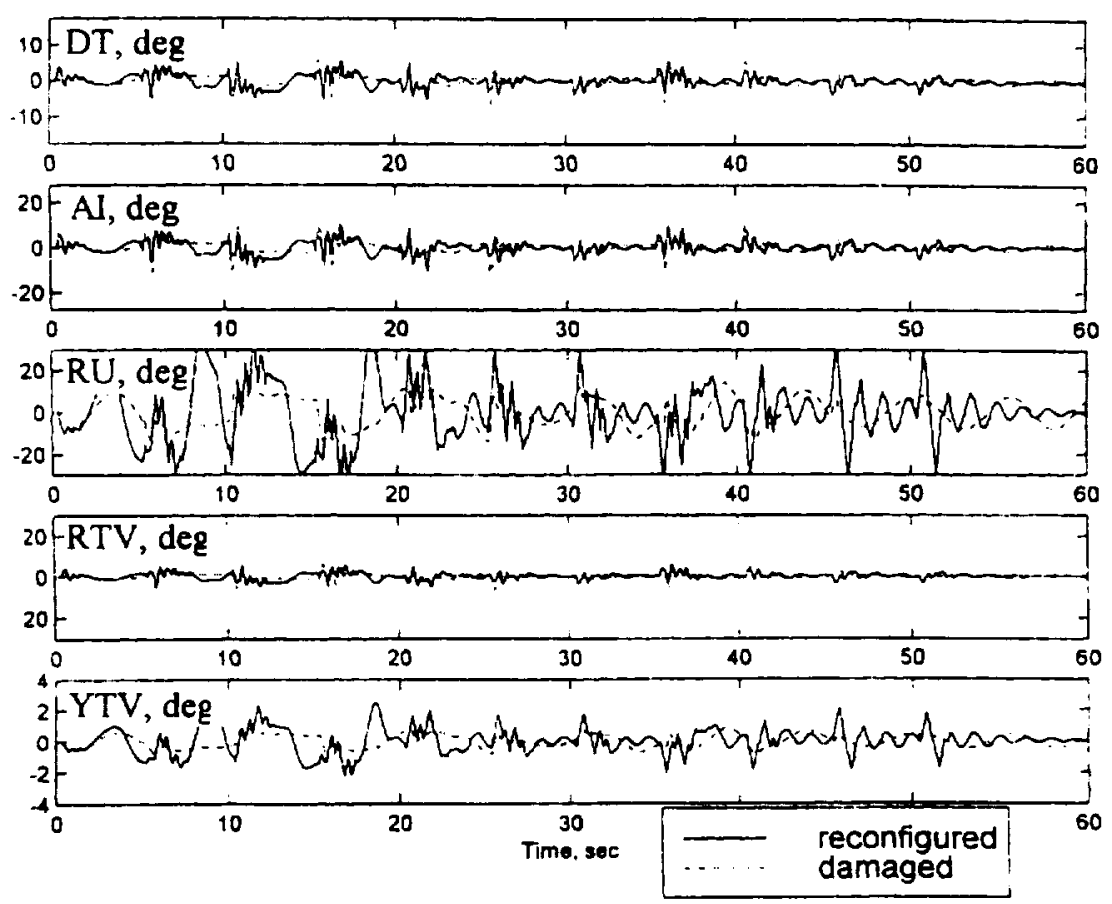

Figure 24 Actuator amplitudes for damaged and reconfigured vehicle (during and after reconfiguration)

19

American Institute of Aeronautics and Astronautics 

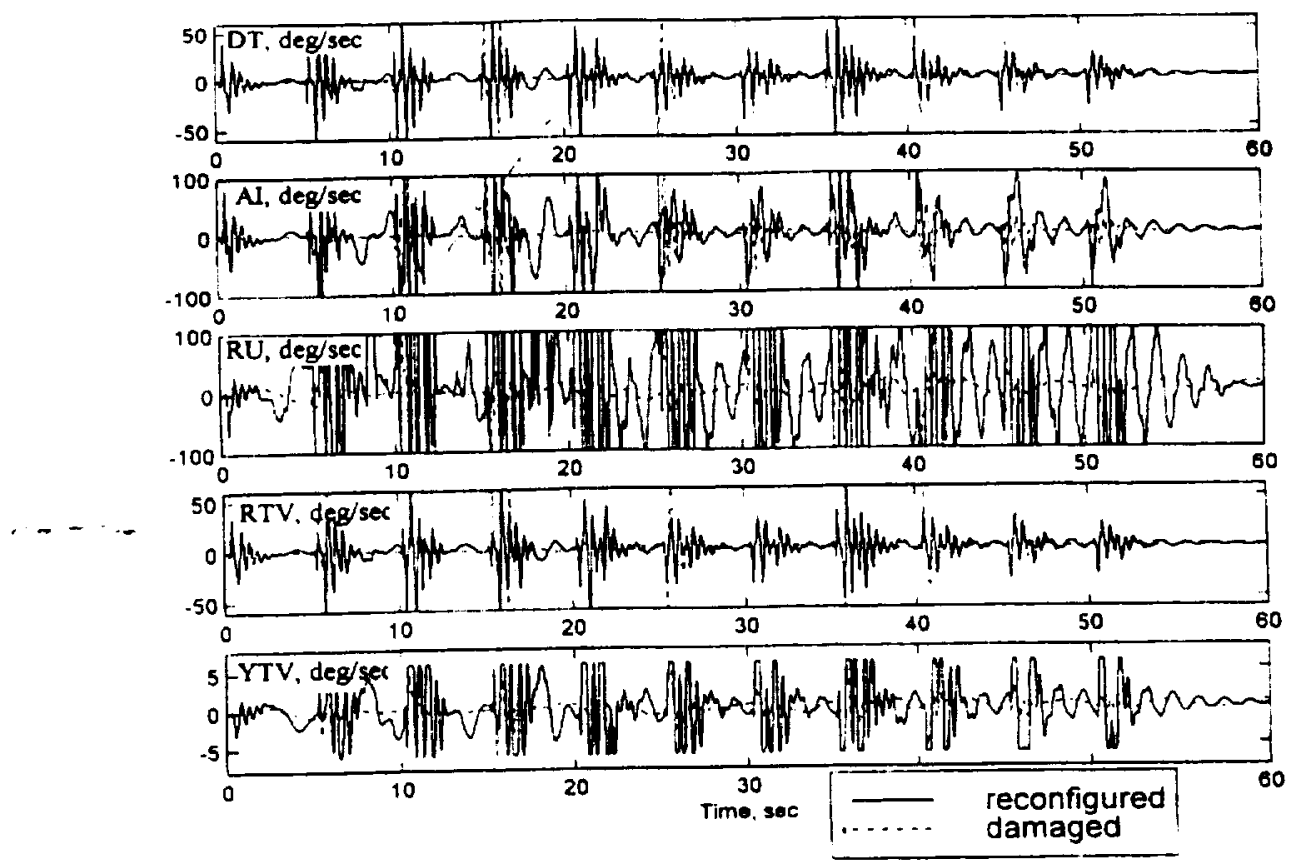

Figure 25 Actuator rates for damaged and reconfigured vehicle (during and after reconfiguration) 